\title{
Social class and cancer survival in Turin, Italy
}

\author{
Stefano Rosso, Fabrizio Faggiano, Roberto Zanetti, Giuseppe Costa
}

\begin{abstract}
Study objective - This study aimed to investigate social differences in cancer survival in residents of Turin, Italy.

Design-Incident cases from the Piedmont cancer registry were linked to municipality files and 1981 census data, and followed up from 1985-92. The census provided data on education and housing tenure, which were used as indicators of social class. The case fatality ratio (CFR) was estimated through a proportional hazard model, with socioeconomic indicators as risk factors. Main results - Educated people of both sexes showed better survival for all malignant neoplasms together and, particularly among men, for tumours which show a better prognosis such as cancer of colonrectum, larynx, prostate, and bladder. The relative risk of dying, compared with people who had only primary school education, decreased from 0.91 for those with middle school education to 0.67 for those who held a university degree.

Conclusion - There were major differences in cancer survival showing a poorer outcome for those from the lower social stratum, particularly in sites for which effective treatments are available. Since is unlikely that the observed differences could be totally explained by extraneous factors, such as competing mortality, it is concluded that even in a country where the health system offers universal coverage, nonfinancial barriers act by creating differences in opportunities for better care.
\end{abstract}

(F Epidemiol Community Health 1997;51:30-34)

Large differences in incidence in relation to social class have been observed in developed countries for many tumour sites. ${ }^{1-6}$ These differences can be accounted for in several ways, for example, the differential magnitude of exposures to risk factors in terms of specific agents, such as chemicals in the workplace, or in terms of more general patterns of risk such as diet, tobacco smoking, or reproductive behaviour. As for tumours in which the effectiveness of preclinical diagnosis is recognised (breast and cervical cancers), differences in the incidence of advanced lesions or in mortality could reflect inequalities of access to screening services.

Differences in survival are a more complex subject. Since most of the evidence on survival differences comes from cancer registries, which often do not collect information on disease stages, observed differences can be due either to true effects or to artefacts. Among the artefacts one can include:
1. Lead time bias: people from higher social groups may have more prompt access to diagnosis and treatment services, early diagnosis, and therefore lengthening the survival time, even without alteration of the natural history of the disease;

2. Effect of competitive causes of death: social differences in general mortality are well documented in many industrialised countries, ${ }^{7}$ but it is not always possible to control for these factors by computing relative survival using social class-specific life tables;

3. Confounding: some factors, such as marital status or place of residence, can be correlated to both social status and compliance to treatment, thus playing a confounding role in the analysis of survival; and

4. Casual fluctuations when the number of cases followed up is small.

Social differences in survival can be true effects due to:

1. Delays - diagnostic delay, for example, can result in more advanced stages at presentation and reduce the efficacy of treatment;

2. Restricted access to better treatments;

3. Disparities in the quality of general care (independent of specific treatments); and 4. Inequalities in access to effective screening programmes.

International reports vary widely depending on countries and cancer sites. The excesses in mortality among socially disadvantaged cancer patients compared with those from higher socioeconomic groups are generally higher than $25 \%$ in the USA $\left(28 \%{ }^{8}\right)$, while they are lower in the UK $\left(\operatorname{men}=20 \%\right.$; women $\left.=12 \%^{2}\right)$, Canada $\left(\operatorname{men}=11 \%\right.$; women $\left.=25 \%{ }^{9}\right)$, and Sweden (approximately $10 \%^{5}$ ). They seem to be higher for cancer sites with a good prognosis, like colon cancer (USA - men $=45 \%$, women $=$ $42 \%{ }^{10}$; $>200 \%{ }^{8}$; UK - men $=44 \%$, women $=$ $12 \%^{2}$; Sweden - about $27 \%{ }^{5}$ ) than for cancer sites with a poor prognosis, like lung cancer (USA - $\operatorname{men}=4 \%{ }^{10}$; UK $-\operatorname{men}=8 \%$; women $=13 \%^{2}$; Sweden - no differences ${ }^{5}$ ).

Even though no published data on social differences in cancer survival are available for Italy, and despite the principle of equal access to the national health service, data on social differences in incidence ${ }^{1}$ and mortality ${ }^{11}$ show that access to health services and effective screening programmes can be expected to be influenced by geographical, cultural, and socioeconomic factors, as has been documented in previous studies. ${ }^{12-14}$

In this study, social differences in cancer survival were analysed by using data routinely collected by the Piedmont cancer registry and record linkage with census data which thereby provided individual-based social indicators. 
Methods

SUBJECTS

The present analysis was based on recordlinkage between files of the Piedmont cancer registry, which is population based and covers the urban area of Turin (about one million inhabitants), and 1981 census data on Turin residents through the Turin longitudinal study. This procedure, the details of which are published elsewhere, ${ }^{15}$ allowed us to characterise by social condition 12655 subjects (88.3\%) from the 14330 total incident cases reported to the cancer registry during the period $1985-87 .{ }^{16}$

The main reasons for linkage failure were as follows: immigration after the census time $(5.1 \%)$, errors in residency status $(2.1 \%)$, and other causes ( $4.4 \%)$. All subjects were followed up until the end of March 1993 with a minimum follow up period of 5 years and 3 months. Ten cases $(0.08 \%)$ were lost during follow up.

Cases notified to the cancer registry by means of death certificates only were excluded (635 cases) because it was not possible to trace the exact date of diagnosis and, consequently, to measure their survival time. Subjects less than 25 years old at the time of diagnosis were also excluded because they could not have reached a higher education level and therefore any comparison in relation to level of education would have been biased. Finally, the total number of cases left in the analysis was 11653 .

\section{SOCIAL CLASS INDICATORS}

Following Max Weber's theory on social class, based on the multi-dimensionality of the condition involving status, power, and income, the most used indicators of social class are occupation and education. ${ }^{17}$ At least in Europe, the best known indicator is occupation, and the most common classification was developed by the Registrar General of England and Wales in 1911, and adapted to the changing structure of the society every 10 years. ${ }^{7}$ However, scales based on occupation usually do not consider retired or unemployed people, and they classify only a small proportion of women correctly.

Education, at least partly, is a measure of status and income. Some authors prefer to use education, rather than occupation, as a socioeconomic indicator for adults, mainly because the former applies with equal validity to women and inactive men, and it usually does not change during adult life. ${ }^{18}$

Italy does not have a generally accepted social classification as in Great Britain. Moreover, in a previous study about social inequalities in cancer risk in Turin, education showed a clearer relationship to the risk of cancer than did occupation. ${ }^{1}$ For these reasons, level of education was used in this analysis as an indicator of social class. Using the available census data, the scale used in this analysis was: university degree (more than 15 years of education); high school (12-14 years); middle school (6-11 years); primary school (fewer than 6 years). Information on housing tenure was considered as an indirect measure of income, dividing subjects into two groups, of roughly the same size, owners and tenants.
ANALYSIS

Case fatality ratios (CFR) were estimated through a proportional hazard model, ${ }^{19}$ with socioeconomic indicators as risk factors. The proportionality assumption of models, both graphically and formally, was checked by testing the statistical significance of time-dependent variables. ${ }^{20}$ Since age was highly correlated with survival time, the lack of proportionality was controlled for by means of stratification into two age groups, and a continuous term for age measured in years was included in models as a confounder. In addition, CFR was adjusted for gender, when appropriate, after having carefully checked and excluded interaction with other risk factors. Since area of birth was known as a potential confounder, this factor was also controlled for.

Education and housing tenure were included in models together to take account of the two dimensions of social class as previously defined. The lowest socioeconomic categories (ie, primary school and tenants) were defined as reference categories, based on statistical power considerations.

Confidence intervals were calculated at the $95 \%$ level of significance. In order to evaluate linear trend for education, the variable was treated as continuous in models including other relevant variables.

Tumour sites were selected according to clinical and statistical considerations, by including cancers with at least one hundred incident cases, and by grouping together some sites (oral cavity and pharynx: ICD 140-149; lymphomas and leukaemias: ICD 200-208; colon and rectum: ICD 153-154; central nervous system: ICD 191-192; unspecified and metastasis: ICD 159, 195-199).

\section{Results}

Table 1 shows the CFR for of all neoplasms and for selected sites only in relation to education, since house tenure showed similar results, with a few exceptions presented in the text.

Highly educated people had a significantly better survival for all malignant tumours with a linear decrease of risk of dying from 0.91 for people with a middle school education to 0.67 for people with a university degree, compared with those with only primary school level education. The overall figure was influenced by the different behaviour and distribution of cancers in relation to site and social class.

Cancers of the digestive tract, in general, did not show a clear relationship with education. Only when considering cancers of the colon and rectum was there a significant difference in risk, and this favoured those with the highest levels of education.

Respiratory cancers were mainly represented by lung cancer, for which a clear pattern was not present. On the other hand, cancer of the larynx showed a significant decrease in the CFR from lower to higher education.

In gynaecological cancers, education played a less clear role, while in cervical cancer house tenure was significantly associated with a lower 
Table 1 Case fatality ratio (CFR) in relation to education

\begin{tabular}{|c|c|c|c|c|c|c|}
\hline \multirow[b]{2}{*}{ Site (ICD-9) } & & \multicolumn{4}{|l|}{ Education levels } & \multirow{2}{*}{$\begin{array}{l}p\left(\chi^{2}\right) \\
\text { Trend* }\end{array}$} \\
\hline & & Primary school & Middle school & High school & University & \\
\hline Mouth and pharynx & Noł & $1127 / 202$ & $41 / 62$ & $9 / 16$ & $8 / 14$ & \\
\hline$(140-149)$ & CFRS & 1 & 1.12 & 0.78 & 0.70 & 0.401 \\
\hline$(n=294) f$ & $095 \% \mathrm{CI} \|$ & & $0.78,1.62$ & $0.39,1.55$ & $0.34,1.47$ & \\
\hline Oesophagus & No & $66 / 69$ & $14 / 14$ & $10 / 10$ & $3 / 4$ & \\
\hline$(150)$ & CFR & 1 & 1.82 & 1.49 & 0.49 & 0.990 \\
\hline$(\mathrm{n}=97)$ & $95 \% \mathrm{CI}$ & & $0.94,3.55$ & $0.71,3.13$ & $0.14,1.72$ & \\
\hline $\begin{array}{l}\text { Stomach } \\
\text { (151) }\end{array}$ & $\begin{array}{l}\text { No } \\
\text { CFR }\end{array}$ & $\begin{array}{l}376 / 448 \\
1\end{array}$ & $\begin{array}{l}83 / 97 \\
1.13\end{array}$ & $\begin{array}{l}26 / 34 \\
1.06\end{array}$ & $\begin{array}{l}18 / 20 \\
142\end{array}$ & 0.150 \\
\hline$(n=599)$ & $95 \% \mathrm{CI}$ & & $0.89,1.44$ & $0.710,1.58$ & $0.88,2.30$ & 0.150 \\
\hline Colon-rectum & No & $573 / 795$ & $184 / 293$ & $71 / 117$ & $47 / 85$ & \\
\hline $\begin{array}{l}(153-154) \\
(n=1290)\end{array}$ & CFR & & 0.89 & 0.83 & 0.67 & 0.007 \\
\hline $\begin{array}{l}(\mathrm{n}=1290) \\
\text { Liver }\end{array}$ & $\begin{array}{l}95 \% \text { CI } \\
\text { No }\end{array}$ & $179 / 181$ & $\begin{array}{l}0.75,1.05 \\
46 / 49\end{array}$ & $\begin{array}{l}0.65,1.07 \\
18 / 22\end{array}$ & $\begin{array}{l}0.52,0.95 \\
9 / 9\end{array}$ & \\
\hline $\begin{array}{l}\text { Liver } \\
(155)\end{array}$ & $\begin{array}{l}\text { No } \\
\text { CFR }\end{array}$ & 1 & $\begin{array}{l}46.49 \\
0.76\end{array}$ & $\begin{array}{l}18 / 22 \\
0.58\end{array}$ & $\begin{array}{l}9 / 9 \\
1.40\end{array}$ & 0.147 \\
\hline$(n=261)$ & $95 \% \mathrm{CI}$ & & $0.53,1.08$ & $0.35,0.96$ & $0.69,2.84$ & \\
\hline Biliary ducts & No & $81 / 85$ & $33 / 36$ & $10 / 11$ & $5 / 5$ & \\
\hline (156) & CFR & & 0.86 & 0.76 & 1.08 & 0.564 \\
\hline$(n=137)$ & $95 \% \mathrm{CI}$ & & $0.56,1.31$ & $0.37,1.56$ & $0.42,2.78$ & \\
\hline Pancreas & No & $167 / 171$ & $53 / 54$ & $28 / 31$ & $7 / 7$ & \\
\hline (157) & CFR & & 1.26 & 0.86 & 1.91 & 0.565 \\
\hline$(n=263)$ & $95 \% \mathrm{CI}$ & & $0.92,1.74$ & $0.57,1.31$ & $0.88,4.14$ & \\
\hline Larynx & No & $99 / 172$ & $24 / 65$ & $12 / 27$ & $3 / 10$ & \\
\hline (161) & CFR & 1 & 0.57 & 0.71 & 0.42 & 0.017 \\
\hline$(\mathrm{n}=274)$ & $95 \% \mathrm{CI}$ & & $0.36,0.90$ & $0.39,1.33$ & $0.13,1.33$ & \\
\hline Lung & No & $955 / 1004$ & $308 / 325$ & $116 / 126$ & $47 / 50$ & \\
\hline$(162)$ & CFR & 1 & 1.07 & 0.96 & 0.93 & 0.825 \\
\hline$(n=1505)$ & $95 \% \mathrm{CI}$ & & $0.94,1.22$ & $0.78,1.16$ & $0.70,1.26$ & \\
\hline Melanoma & No & $24 / 60$ & $13 / 42$ & $15 / 35$ & $3 / 14$ & \\
\hline $\begin{array}{l}(172) \\
(n=151)\end{array}$ & CFR & & 0.81 & 1.32 & 0.46 & 0.728 \\
\hline $\begin{array}{l}(\mathrm{n}=151) \\
\text { Breast }\end{array}$ & $95 \% \mathrm{CI}$ & & $0.39,1.66$ & $0.62,2.79$ & $0.12,1.72$ & \\
\hline $\begin{array}{l}\text { Breast } \\
(174)\end{array}$ & No & $308 / 777$ & $135 / 371$ & $53 / 162$ & $16 / 51$ & \\
\hline $\begin{array}{l}(174) \\
(n=1361)\end{array}$ & CFR & & 1.01 & 0.94 & 0.89 & 0.645 \\
\hline$(n=1361)$ & $95 \%$ CI & & $0.82,1.24$ & $0.70,1.27$ & $0.54,1.49$ & \\
\hline Cervix uteri & No & $72 / 127$ & $17 / 31$ & $7 / 11$ & $2 / 2$ & \\
\hline$(180)$ & CFR & & 1.23 & 1.04 & 3.26 & 0.362 \\
\hline$(n=171)$ & $95 \%$ CI & & $0.99,1.51$ & $0.77,1.41$ & $1.96,5.42$ & \\
\hline Corpus uteri & No & $69 / 168$ & $21 / 56$ & $8 / 26$ & $0 / 1$ & \\
\hline (182) & CFR & & 1.29 & 1.11 & 0.12 & 0.566 \\
\hline$(\mathrm{n}=251)$ & $95 \% \mathrm{CI}$ & & $0.78,2.14$ & $0.52,2.37$ & $0.01,0.28$ & \\
\hline Ovary & No & $98 / 121$ & $36 / 51$ & $20 / 22$ & $1 / 2$ & \\
\hline (183) & CFR & 1 & 0.82 & 1.14 & 0.56 & 0.850 \\
\hline$(\mathrm{n}=196)$ & $95 \% \mathrm{CI}$ & & $0.55,1.36$ & $0.69,1.89$ & $0.08,4.14$ & \\
\hline Prostate & No & $176 / 253$ & $57 / 85$ & $35 / 50$ & $22 / 37$ & \\
\hline (185) & CFR & 1 & 1.12 & 1.28 & 0.84 & 0.924 \\
\hline$(n=425)$ & $95 \% \mathrm{CI}$ & & $0.83,1.52$ & $0.88,1.86$ & $0.54,1.32$ & \\
\hline Bladder & No & $249 / 462$ & $77 / 164$ & $32 / 83$ & $18 / 38$ & \\
\hline$(188)$ & CFR & 1 & 0.96 & 0.74 & 0.82 & 0.131 \\
\hline$(\mathrm{n}=747)$ & $95 \% \mathrm{CI}$ & & $0.74,1.25$ & $0.50,1.07$ & $0.50,1.33$ & \\
\hline Kidney & No & $97 / 143$ & $50 / 76$ & $18 / 27$ & $6 / 12$ & \\
\hline$(189)$ & CFR & 1 & 1.01 & 1.04 & 0.60 & 0.465 \\
\hline$(\mathrm{n}=258)$ & $95 \% \mathrm{CI}$ & & $0.70,1.43$ & $0.60,1.81$ & $0.26,1.40$ & \\
\hline Brain & No & $90 / 99$ & $28 / 33$ & $14 / 17$ & $9 / 10$ & \\
\hline$(191-192)$ & CFR & & 0.78 & 0.87 & 0.66 & 0.223 \\
\hline$(\mathrm{n}=159)$ & $95 \% \mathrm{CI}$ & $0.51,1.25$ & $0.41,1.81$ & $0.32,1.37$ & & \\
\hline Thyroid & No & $17 / 43$ & $5 / 18$ & $1 / 10$ & $1 / 4$ & \\
\hline (193) & CFR & 1 & 1.33 & 1.55 & 4.64 & 0.277 \\
\hline$(n=75)$ & $95 \% \mathrm{CI}$ & & $0.39,4.60$ & $0.12,20.32$ & $0.44,49.39$ & \\
\hline Undefined or MTS & No & $219 / 227$ & $68 / 72$ & $22 / 25$ & $10 / 11$ & \\
\hline$(159,195-199)$ & CFR & 1 & 0.90 & 0.77 & 0.68 & 0.107 \\
\hline$(\mathrm{n}=335)$ & $95 \% \mathrm{CI}$ & & $0.68,1.20$ & $0.49,1.21$ & $0.36,1.30$ & \\
\hline Lymphomas, leukemias & No & $256 / 312$ & $104 / 137$ & $38 / 58$ & $13 / 23$ & \\
\hline$(200-208)$ & CFR & 1 & 0.89 & 0.70 & 0.48 & 0.003 \\
\hline$(\mathrm{n}=530)$ & $95 \% \mathrm{CI}$ & & $0.70,1.14$ & $0.49,1.00$ & $0.27,0.85$ & \\
\hline All sites & No & $4636 / 6872$ & $1504 / 2527$ & $615 / 1137$ & $277 / 517$ & \\
\hline$(140-208)$ & CFR & 1 & 0.91 & 0.80 & 0.67 & $<0.001$ \\
\hline$(\mathrm{n}=11053)$ & $95 \% \mathrm{CI}$ & & $0.86,0.97$ & $0.73,0.87$ & $0.61,0.78$ & \\
\hline All sites but 173 & No & $4600 / 6320$ & $1493 / 2271$ & $607 / 1003$ & $268 / 434$ & \\
\hline & CFR & 1 & 0.94 & 0.85 & 0.73 & $<0.001$ \\
\hline$(n=10028)$ & $95 \% \mathrm{CI}$ & & $0.88,0.99$ & $0.78,0.93$ & $0.65,0.83$ & \\
\hline
\end{tabular}

${ }^{*} \mathrm{p}\left(\chi^{2}\right)$ for trend of education; $\dagger$ cases at the beginning of follow up; $\neq$ dead/all cases at the end of follow up; $\uparrow$ case fatality ratio adjusted for age, area of birth, sex, and housing tenure; $\| 95 \%$ confidence interval.

risk for owner-occupiers $(\mathrm{CRF}=0.75 ; 95 \% \mathrm{CI}$ $0.63,0.89$ ).

Low education was only weakly associated with the risk of dying from prostatic cancer, but house owners showed a significantly lower risk $(C R F=0.77 ; 95 \%$ CI $0.61,0.98)$. A similar pattern was also present in bladder cancer with a CFR of 0.70 for house owners (95\% CI 0.57 , 0.87).

For lymphomas and leukaemias, grouped together here in order to improve statistical power, higher education maintained a protective effect, with a CFR of 0.48 for people with a university degree, and there was a significant linear trend. Within this group, leuk- aemia and non-Hodgkin's lymphomas were the main subgroups responsible for this result, although low numbers decreased the power of statistical comparisons.

Malignant melanoma did not show any particular risk pattern, except for the shorter survival in men. As has already been seen in other studies, ${ }^{21}$ this effect is partly due to the different site distribution of cutaneous malignant melanoma (CMM) in men and women, since CMM on the limbs, which occurs more frequently in women, has a better survival than CMM on other sites.

Finally, we analysed survival grouping cancers in relation to the prognosis. Those showing 
Table 2 Case fatality ratio (CFR) and education in relation to sex and prognostic groups

\begin{tabular}{|c|c|c|c|c|c|c|}
\hline \multirow[b]{2}{*}{ Site (ICD-9) } & & \multicolumn{4}{|l|}{ Education levels } & \multirow{2}{*}{$\begin{array}{l}p\left(\chi^{2}\right) \\
\text { Trend* }\end{array}$} \\
\hline & & Primary school & Middle school & High school & University & \\
\hline \multicolumn{7}{|l|}{ Males } \\
\hline $\begin{array}{l}\text { Cancers with a good prognosis** } \\
(n=1771) \dagger\end{array}$ & $\begin{array}{l}\text { Noł } \\
\text { CFR@ } \\
95 \% \text { CI }\end{array}$ & $\begin{array}{l}429 / 991 \\
1\end{array}$ & $\begin{array}{l}121 / 393 \\
0.77 \\
0.63,0.95\end{array}$ & $\begin{array}{l}77 / 25 \\
0.76 \\
0.60,0.98\end{array}$ & $\begin{array}{l}38 / 130 \\
0.67 \\
0.48,0.94\end{array}$ & $<0.001$ \\
\hline $\begin{array}{l}\text { Cancers with a poor prognosistt } \\
(\mathrm{n}=1989)\end{array}$ & $\begin{array}{l}\text { No } \\
\text { CFR } \\
95 \% \text { CI }\end{array}$ & $\begin{array}{l}1242 / 1300 \\
1\end{array}$ & $\begin{array}{l}394 / 414 \\
1.07 \\
0.82,1.38\end{array}$ & $\begin{array}{l}170 / 188 \\
0.91 \\
0.68,1.28\end{array}$ & $\begin{array}{l}83 / 87 \\
0.92 \\
0.68,1.38\end{array}$ & 0.462 \\
\hline Females & & & & & & \\
\hline $\begin{array}{l}\text { Cancers with a good prognosis } \\
(\mathrm{n}=2465)\end{array}$ & $\begin{array}{l}\text { No } \\
\text { CFR } \\
95 \% \text { CI }\end{array}$ & $\begin{array}{l}571 / 1485 \\
1\end{array}$ & $\begin{array}{l}210 / 631 \\
0.97 \\
0.83,1.14\end{array}$ & $\begin{array}{l}74 / 263 \\
0.83 \\
0.65,1.07\end{array}$ & $\begin{array}{l}24 / 86 \\
0.91 \\
0.60,1.38\end{array}$ & 0.213 \\
\hline $\begin{array}{l}\text { Cancers with a poor prognosis } \\
(\mathrm{n}=877)\end{array}$ & $\begin{array}{l}\text { No } \\
\text { CFR } \\
95 \% C I\end{array}$ & $\begin{array}{l}580 / 602 \\
1\end{array}$ & $\begin{array}{l}180 / 195 \\
0.87 \\
0.62,1.28\end{array}$ & $\begin{array}{l}59 / 65 \\
0.80 \\
0.68,1.28\end{array}$ & $\begin{array}{l}12 / 15 \\
0.58 \\
0.36,1.10\end{array}$ & 0.009 \\
\hline
\end{tabular}

${ }^{*} p\left(\chi^{2}\right)$ for trend of education; †Cases at the beginning of follow up; $\ddagger$ Dead/all cases at the end of follow up; §Case fatality ratio (adjusted by age, area of birth, sex and housing tenure); $\| 95 \%$ confidence intervals.

** Cancers (ICD-9) with a good prognosis: males $140,142,161,172,173,186,188,193,201$; females $140,142,161,172,173,174$, $180,188,193,201$;

+ Cancers (ICD-9) with a poor prognosis: 150,155,156,157,162,191,195-199,205.

$60 \%$ survival or more at 3 years were deemed to be cancers with a good prognosis and those which showed $25 \%$ survival or less at 1 year were cancers with a worse prognosis. Socioeconomic differences in the risk of dying were generally present in both groups and sexes, but education had a stronger effect on survival for cancer with a good prognosis, particularly in men (table 2). In contrast, women showed a more evident effect of socioeconomic indicators in cancers with a poor prognosis.

\section{Discussion}

A 1985-92 mortality follow up of the 1985-87 incidence cancer series of the city of Turin showed significant social differences in survival. People from the lower educational level category showed an excess mortality of about $50 \%$ compared with people who had graduated from university. This excess seems higher than that found in other countries (USA - $28 \%{ }^{8}$; Canada men $=11 \%$, women $=25 \%{ }^{9}$; UK: men $=11 \%$; women $=26 \%^{2}$ ). Our data showed that people in lower level education groups were disadvantaged in terms of survival and that this might be explained by differences in access to effective treatments. In particular, figures for men confirm clearly the hypothesis of inequality in care since the social differences are concentrated in cancers with a good prognosis. Those for women are more complex. Fatality rates for cancers with a good prognosis showed a weaker trend when compared with those in men; in fact $62 \%$ of these cases were breast and cervix cancers which have low trends. The survival for poor prognosis cancers among women showed a strong tendency to be higher among more privileged people, in contrast with the figures for men and with the expected profile. This might be due to a lead time effect. That is, high socioeconomic groups would receive a prompter diagnosis than less privileged people - the natural course of the disease does not change, but simply the time since diagnosis increases. Even if it produces a small increase, it becomes relevant when the total survival time is short.

If access to treatment plays such an important role in promoting social differences in survival, an effect can be detected for those cancers where cytotoxic treatments are effective such as cancer of the testis, ovary, and some neoplasms of haemopoietic system (in particular Hodgkin's disease).$^{22}{ }^{23}$ Moreover surgery appears to be effective in colonic, laryngeal, and bladder cancers. In our study, neoplasms of the haemopoietic system and colorectal and laryngeal cancers showed the highest differences in survival, to the detriment if the lower social class. Among sites for which effective treatment exists, only cancer of the ovary did not show a similar profile. On the other hand, treatment for cancer of the ovary is effective only in early stages and in our population patients are not usually seen before the disease is more advanced. Data from Sweden and United Kingdom confirm the Italian profile: high social differences were found for colorectal (USA - $170 \%$ of excess ${ }^{8}$; Sweden $27 \%^{5}$; UK - men $=44 \%$, women $=12 \%{ }^{2}$ ) and bladder cancers (Sweden $-7 \%{ }^{5}$; UK - men $=$ $22 \%$, women $=41 \%^{2}$ ), while smaller differences are found for cancer of the ovary (Sweden $-4 \%^{5}$; UK $-14 \%^{2}$ ).

Early diagnosis can also contribute to the prognostic advantage of the upper classes. ${ }^{23}$ In Turin, Vines et $a l^{4}$ found that people from lower social levels had a fivefold increase in the probability of being admitted to hospital treatment with more advanced stages of colorectal cancer than those from the upper levels. In the United Kingdom, stomach cancer showed a $10 \%$ excess of mortality among housing tenants compared with owner-ocupiers; the figures for oesophageal cancer for men and women were $11 \%$ and $26 \%$ respectively and for cancer of the pancreas they were $11 \%$ and $51 \%$ respectively. ${ }^{2}$ No differences were found in Sweden for pancreatic cancer. ${ }^{5}$ Even breast cancer, which is expected to be partially influenced by both stage and treatment, showed only a slight indirect correlation of mortality with social class. On the other hand, breast cancer survival data from Sweden and UK showed only slight social differences (Sweden $11 \%$ and $2 \%$ for the UK).

The case of breast cancer is in some way similar to that of cancer of the cervix uteri. No relevant differences in educational level were 
Table 3 Cancer incidence, mortality, and case fatality ratio (CFR) in relation to education in Turin during the 1980s (all neoplasms)

\begin{tabular}{lllll}
\hline & \multicolumn{3}{l}{ Education level } \\
\cline { 2 - 5 } & Primary school & Middle school & High school & University \\
\hline Incidence (1985-87) Odds ratio & 1.15 & 1.04 & 1.03 & 1 \\
Mortality (1985-88) Risk ratio & 1.49 & 1.43 & 1.20 & 1 \\
Fatality (1985-93) CFR & 1.37 & 1.29 & 1.16 & 1 \\
\hline
\end{tabular}

found for either, although housing tenure affected survival for cervical cancer in spite of the relative effectiveness of available treatment. Besides, in both cases early diagnosis practices are known to be effective and could play a part. On the basis of the evidence of higher aggressiveness of undetected cervical ${ }^{25}$ and breast cancers, ${ }^{26}$ it is possible to argue that women attending effective screening more frequently could have experienced higher fatality rates, owing to the greater aggressiveness of cancers missed by screening practices. In fact, a previous study held in Turin documented a difference in attendance rates in relation to social class for breast and cervical cancer, with rates ranging from $52 \%$ and $44 \%$ (for breast and cervical cancer respectively) for less educated women to $80 \%$ and $64 \%$ for graduands. ${ }^{13}$

In our analysis, the documented differences could also partially be attributable to competing cause of death. Indeed, the 1981-85 mortality data for Turin showed that those with a lower educational level were at higher risk for death from non-cancer causes that people (of both genders) who had a university degree. ${ }^{27}$ Differential risk of dying from non-cancer causes among cancer patients could therefore produce differences in survival. To try to measure the extent of this effect, table 3 compares cancer fatality in relation to education with data on cancer incidence ${ }^{1}$ and mortality (ad hoc analyses). The effect of social class is moderate for incidence but there is a substantial increase in mortality. This increase appears to be mostly due to differences in fatality, which seems to contribute with incidence results to mortality trends. This is indirect evidence that competing mortality cannot explain our results, and therefore the figures presented can be considered reliable.

In conclusion, there were major differences in survival among social classes, measured by educational level. These differences were particularly high when effective treatments were available, suggesting differential access to effective cancer care among social classes. However, no differences were found for cancers for which an early stage at diagnosis is recognised as an important prognostic factor. This finding, which could suggest egalitarian access to health care services, can be interpreted rather as a balanced effect of social discrimination in access to care and of the greater aggressiveness of tumours that are not detected by screening. It seems evident that discrimination in access to care contributes substantially to social differences in health. Even in countries where a public health system is widespread and can offer universal coverage, non-financial barriers contribute to differential opportunities for better care and people cannot attain equivalent survival. These findings suggest the need to implement studies on the role of non-financial barriers in accessing care so as to plan structural interventions aimed at improving equity in care.

This study was made possible by the support of: Associazione Italiana per la Ricerca sul Cancro, Italy and Consorzio Sistem Informativi Piemonte, Italy.

1 Faggiano F, Zanetti R, Costa G. Cancer risk and social inequalities in Italy. $\mathcal{F}$ Epidemiol Community Health 1994; 48:447-52.

2 Kogevinas M. Longitudinal study: socio-demographic differences in cancer survival. OPCS, London: HMSO, 1990.

3 Lynge E, Thygesen L. Occupational cancer in Denmark. Copenhagen: 1990.

4 Pukkala E. Cancer risk by social class and occupation. Contributions to epidemiology and Biostatistics. Vol 7. Basel: tributions to

5 Vagerö D, Persson G. Occurrence of cancer in socioeconomic groups in Sweden. An analysis based on the Swedish cancer environment registry. Scand $\mathcal{f}$ Soc Med 1986;14:151-60.

6 Williams RR, Horm JW. Association of cancer sites with tobacco and alcohol consumption and socioeconomic status of patients: Interview study from the third national cancer survey. $\mathcal{F}$ Natl Cancer Inst 1977;58:525-47.

7 Logan WPD. Cancer mortality by occupation and social class, studies on medical and population subjects no 44. London: HMSO; Lyon, International Agency for Research on Cancer, 1982 .

8 Chirikos TN, Reiches NA, Moeschberger ML. Economic differentials in cancer survival: a multivariate analysis. $\mathcal{F}$ differentials in cancer survi

9 Stavraky KM, Kincade JE, Stewart MA, Donner AP. The effect of socioeconomic factors on the early prognosis of cancer. F Chron Dis 1987;40:237-44.

10 Lipwort L, Abelin T, Connelly RR. Socioeconomic factors in the prognosis of cancer patients. F Chron Dis 1970;23: 105-16.

11 Faggiano F, Lemma P, Costa G, Gnavi R, Pagnanelli F. Cancer mortality by educational level in Italy. Cancer Causes Control 1995;6:311-320.

12 Ferraroni M, La Vecchia C, Pagano R, Negri E, Parazzin C, Decarli A. Pattern of cervical screening utilization in Italy. Tumori 1989;75:521-5.

13 Segnan N, Ronco G, Ponti A. Practice of early diagnosis of breast and uterine cervix cancer in a northern Italian town. Tumori 1990;76:227-33.

14 La Vecchia C, Negri E, Pagano R, Decarli A. Education, prevalence of diseases, and frequency of health utilisation. prevalence of diseases, and frequency of health

15 Costa G. Demaria M. Un sistema longitudinale di sorcosta $G$. Demaria $M$. Un sistema longitudinale di sor-
veglianza della mortalità secondo le caratteristiche socioeconomiche, come rilevate ai censimenti di popolazione: descrizione e documentazione del sistema. Epidemiologia e prevenzione 1988;36:37-47.

6 Zanetti R, Vicari P, Rosso S, Foggetti R, Anglesio E, Ra dassao $M$. Cancer incidence in Torino, Italy, 1985-87. In: Parkin DM, Muir CS, Whelan SL, Gao Y-T, Ferlay $\mathrm{J}$, Powell J eds. Cancer incidence in five continents - Vol VI IARC Scientific Publications no 120. Iyon: International Agency for Research on Cancer, 1992:654-7.

17 Liberatos P. Bruce GL, Kelsey JL. The measurement of social class in epidemiology. Epidemiol Rev 1988;10:87121

18 Valkonen T. Adult mortality and level of education: A comparison of six countries. In: Fox J, ed. Health in-

19 Cox DR. Regression models in life tables (with discussion) fournal of the Royal Statistical Society B 1972;34:187-220.

20 Kalbfleisch JD, Prentice RL. The statistical analysis of failure time data. New York: John Wiley \& sons, 1980:134-5.

21 Karjalainen S, Hakulinen T. Survival and prognostic factors of patients with skin melanoma. A regression-model analysis based on nationwide cancer registry data. Cancer 1988;62:2274-80.

22 Souhami R, Tobias J. Cancer and its management. Oxford: Blackwell Scientific Publications, 1986.

23 Coebergh JWW. Summary and discussion of results. In: Berrino F, Sant M, Verdecchia A, Capocaccia R, Hakulinen T, Esteve J, eds. Survival of cancer patients in Europe -The EUROCARE study. IARC Scientific Publications no 132. EUR: International Agency for Research on Cancer, 1995:447-63.

24 Vineis P, Fornero G, Magnino A, Giacometti R, Ciccone G. Diagnostic delay, clinical stage and social class: a hospital based study. $\mathcal{f}$ Epidemiol Community Health, 1993; 47: 229-31.

25 Ponten J, Adami H-O, Bergstrom R et al. Strategies for global control of cervical cancer. Int $\mathcal{f}$ Cancer, 1995;60: global

$26 \mathrm{Klemi}$ PJ, Joensuu H, Toikkanen S, et al. Aggressiveness of breast cancers found with and without screening. $B M F$ 1992;304:467-69.

27 Faggiano F, Costa G. Classe sociale e mortalità in Torino negli anni 80. POLIS 1990;4:471-96. 